\title{
C-E Interpreting of Political Neologisms in Light of Searle's Network-background Theory
}

\author{
Xiaowen Ji \\ University of Shanghai for Science and Technology, Shanghai, China
}

\begin{abstract}
Searle believes that language meaning is determined by intentional states, and is hugely influenced by social rules and communicators' mental capabilities, concluding his Network-Background Theory in his discussion of Intentionality. Contemporary Chinese political discourse has its own distinctiveness, and is especially featured by increasing political neologisms, posing difficulties for interpreters and for China's international publicity. Interpreting of Chinese political neologisms, also for the purpose of conveying language meaning can gain guidance from Searle's Network-Background Theory. This paper elaborates through exemplification on strategies for interpreting political neologisms in light of Searle's theory.
\end{abstract}

Index Terms - Searle, Network-Background Theory, political neologism, C-E interpreting

\section{INTRODUCTION}

China's reform and opening up have injected momentum to its accumulation of comprehensive national strength and global economic and cultural exchanges. Uniqueness of China's political systems and tremendous changes thus brought about are reflected in language use, so contemporary Chinese political discourse has its own distinctiveness with especially the booming of political neologisms, which poses difficulties for interpreters.

Searle's philosophy has been delved into by many domestic and foreign scholars who mainly focus on the Speech Acts Theory, the Chinese Room Argument, and the Collective Intention Theory. However, given a significant role of Network-Background Theory in studies about language meaning, such as linguistic philosophy, relevant research is far lagging behind.

As interpreting is essentially a communicative activity and interpreters are working to convey language meaning, interpreting of Chinese political neologisms can also gain guidance from Searle's Network-Background Theory.

This paper introduces Searle's Intentional Theory of Meaning, and brings his Network-Background Theory in focus to explore strategies for interpreting flourishing Chinese political neologisms in light of Searle's theory.

\section{SeARLE'S InTENTIONAL TheORY OF MEANing}

Intentionality is a philosophical concept defined by The Stanford Encyclopedia of Philosophy as "the power of minds to be about, to represent, or to stand for, things, properties and states of affairs". (Jacob 2010) Franz Brentano introduced the concept of Intentionality to modern philosophy from Medieval Scholastic philosophy, so "Brentano's problem", as is called, is the problem of how to accommodate intentional notions within a naturalistic view of the world. Brentano's thesis that the intentional is the mark of the mental also came to be known. (Mason, Sripada \& Stich 2011, p. 32) Later the philosophers and psychologists who studied with Brentano and were essentially influenced by him formed the School of Brentano with Intentionality as its theme. Among Brentano's students, Edmund Husserl is the most accomplished whose studies of meaning concern logic, linguistics and epistemology. After Husserl, H. P. Grice and John Searle also put forward their own intentional theories of meaning in analyzing ordinary language. Husserl, Grice and Searle are the three main representatives of intentional theories of meaning.

The intentional theory of meaning turns over the traditional formal analysis and takes into account human factors when analyzing language meaning. (Huang Birong 2010, p. 1) According to this theory, meaning relates closely with the speaker's intention, and the psychological intention of the speaker carries meaning. This theory has become an important option among numerous meaning theories at present and plays a revolutionary and groundbreaking role. From the linguistic point of view, it succeeds in expanding the scope of the semantic analysis; from the perspective of philosophy, it helps to figure out the philosophy of mind as the basis for language meaning so as to introduce the language philosophy into the philosophy of mind. Moreover, it probes into meaning generating and understanding through syntactic, semantic and pragmatic amalgamation. (Huang Birong 2010, p. 1)

Searle's philosophy features the combination of linguistic philosophy and philosophy of mind. His study of Intentionality originated from his research on language meaning, the core of which is how language represents reality. Searle found that linguistic representation is not intrinsic in language but derives from Intentionality of the mind. (Searle 2001, p. 153) Searle made three distinctions to distinguish Intentionality from other similar notions: a) psychological states or events with Intentionality are differentiated from those without, "beliefs" being an example of the former as they concern things other than self while inexplicable anxiety being an instance of the latter as it doesn't 
have a direction towards a specific object; b) consciousness and Intentionality are not identical with some unconscious beliefs serving as an illustration; c) "Intending" is just a kind of intentional form, like "beliefs", and thus should be discriminated from Intentionality. (Searle 1983, pp. 1-3) Searle points out that every intentional state has its conditions of satisfaction. Only when one is conscious of a certain state can consciousness possess Intentionality. According to Searle, there are two levels of Intentionality, namely the intentional state of affair expressed (the intention to represent) and the speaking intentional state of affair (the intention to communicate), the former called "bona fide condition" and the latter "meaning intention". (Xu Haiming 1998, p. 68)

Searle takes social rules into consideration when he talks about Intentionality, and moreover, brings forward a systematical theory of meaning from the Intentionality perspective for the first time. He genuinely exploits intentional dimension of the theory of meaning. This is where his Network-Background theory comes into focus.

\section{SEARLE’S NETWORK-BACKGROUND THEORY IN FOCUS}

The Network-Background Theory is one of the most central theories in Searle's discussion of Intentionality. In the Theory of Speech Acts, Searle made an inquiry into "how the intention comes into being" after exploring language meaning, resulting in the Network-Background Theory.

From Searle's point of view, meanings of speech acts take root in the intentional states of the speaker, without which, there would be no meaning. But different from Grice, Searle points out clearly that meanings of speech acts are not only related with Intentionality, but also with customs. Meanings are decided jointly by both Intentionality and customs. (Searle 1955) Customs and social rules are realized by the Intentional Network and the nonrepresentational Background in the process of producing meaning. Therefore, the key to understanding Searle's internalist theory of meaning is to understand his account of the Intentional Network and the nonrepresentational Background. Intentional contents have the decisive influences upon the conditions of satisfaction of intentional states. But these influences are not realized in an independent, atomist way. Each intentional state has its intentional content in the relationship with other innumerable intentional states, or in the Network of intentional states. Moreover, the whole Network can only function against the Background, which is the so-called nonrepresentational mental capability. (Searle 1983, pp. 20-21)

A complete Network of intentional states is composed of all kinds of intentional states, each functioning relying on the Network. Every intentional state has its only condition of satisfaction which in turn is determined by this very intentional state. Or any specific intentional state has only one condition of satisfaction which corresponds with its position in the Network. (Searle 1983, pp. 20-21) The ultimate basis for forming intentional states is the nonrepresentational Background, the human-specific mental capability. This Background isn't any intentional state, but life experience. To be specific, nonrepresentational Background refers to the capability to create and interpret meanings from context of situation, cognitive ability to predict how things develop under specific context, and the psychological and neurological activities involved. (Searle 1983, p. 20)

Interpreting, essentially a communicative activity of conveying meaning can draw insights from Searle's Network-Background Theory. So to ensure the success of interpreting, interpreters also need to improve their knowledge structures to have a better understanding of the Network and of the condition of satisfaction of certain intentional states and to correctly judge the situational context to enrich the Background knowledge. In the following, the author would like to elaborate on interpreting Chinese political neologisms in light of Searle's theory.

\section{Features of Chinese Political Neologisms}

Political neologisms often appear in political discourse, and it is significant to examine the broader context first.

Various definitions of "discourse" are given by scholars. Routledge Dictionary of Language and Linguistics (Bussmann 1996) defines it as "generic term for various types of text" and summarizes some scholars' views, "connected speech (Harris 1952); the product of an interactive process in a sociocultural context (Pike 1954); performance (van Dijk 1974); talk (Cicourel 1975); conversational interaction (Coulthard 1977); 'language in context across all forms and modes' (Tannen 1981); and process (Brown and Yule 1983).” Jaworski and Coupland (1999, pp. 1-3) list ten of its definitions, which can fall into three categories. Discourse is a unit above the sentence or above the clause; discourse is language in use; discourse is a type of social practice. Other definitions are given by Widdowson (1979), Steiner and Veltmen (1988), Kransch (1988), etc. (Li Yue'e \& Fan Hongya 2002, p. 4) According to Foucault (1984, pp. 108-138), discourse is closely connected with power and knowledge because “... in every society the production of discourse is at once controlled, selected, organized and redistributed by a certain number of procedures whose role is to ward off its powers and dangers...".

As to the term "political discourse", such scholars as Wilson, McNair, Chilton \& Schäffner, van Dijk, etc. have all defined it. For instance, Wilson (1990, p.4) restricts it to "the real-world linguistic activities of practising politicians", roughly agreed on by Chilton \& Schäffner (1997, pp. 206-230) and van Dijk (2001, pp. 352-371), while McNair (1995, p. 4) believes it to be all kinds of "purposeful communication about politics". This paper, based on a roundup and analysis of previous views, deems "political discourse" as written or oral language used under political contexts, e.g. in political documents or on political occasions for certain goals.

Mastery of features of political neologisms that have seen a boom in their number in political discourse is an asset for 
exploring strategies to interpret them.

First and foremost, some Chinese political neologisms express considerable amount of information within a few characters. Linguistic simplicity and efficiency of information delivery are accomplished as a natural result of information boom nowadays. Such examples are “打假(da jia)”, “关停并转(guan ting bing zhuan)” and “高官会(gao guan hui)”, which are respectively short for “打击假冒伪劣商品、产品、作品(crack down on counterfeit and shoddy products)”, “对亏损国有企业采取关闭、停产整顿、合并和转产(close, suspend, merge and transition state-owned corporations under deficit)” and “高级官员会议(high-rank officials' meeting)”. Particularly, a large number of political neologisms contain numbers for generalization, such as “三讲(san jiang)”, which refers to “讲学习, 讲政治, 讲正气 (three emphases on theoretical study, political awareness and good conduct)".

Besides, many new political neologisms involve a productive way of word formation, namely affixation. Conventionally affixation is a typical feature of alphabetical languages, but with the growing borrowing trend, such Chinese political neologisms as “特色华(te se hua)”, “智能化(zhi neng hua)”; “透明度(tou ming du)”, “新鲜度(xin xian du)”; “吃喝风(chi he feng)”, “摊派风(tan pai feng)” come into being.

Moreover, rhetorical devices are frequently found in a great number of Chinese political neologisms, mainly for the purposes of clarifying complex thoughts in an acceptable and figurative way for brevity or comprehensibility, and of strengthening or attenuating certain notions. Metaphor is used in “垃圾邮件(la ji you jian)”, “打擦边球(da ca bian qiu)", and “穿小鞋(chuan xiao xie)" to refer "useless mails", “stretching rules to limit", and "receive others' intentional negative influence or retaliation" respectively to "junk", "playing edge ball", and "wearing unfitting shoes".

Additionally, neatly-structured four-character expressions are profusely used. In this new era, many such political neologisms emerge. “高度自治(gao du zi zhi, high degree of autonomy)”, “反腐倡廉(fan fu chang lian, combat corruption and build a clean government)" and “抓大放小(zhua da fang xiao, invigorate large enterprises while relaxing control over small ones)" are good examples.

\section{ESSENCE OF INTERPRETING}

Translation, in essence, is a complex communicative activity. Interpreting, with its time constraints, adds to the directness of the communicative activity, the process of which is quoted as follows.

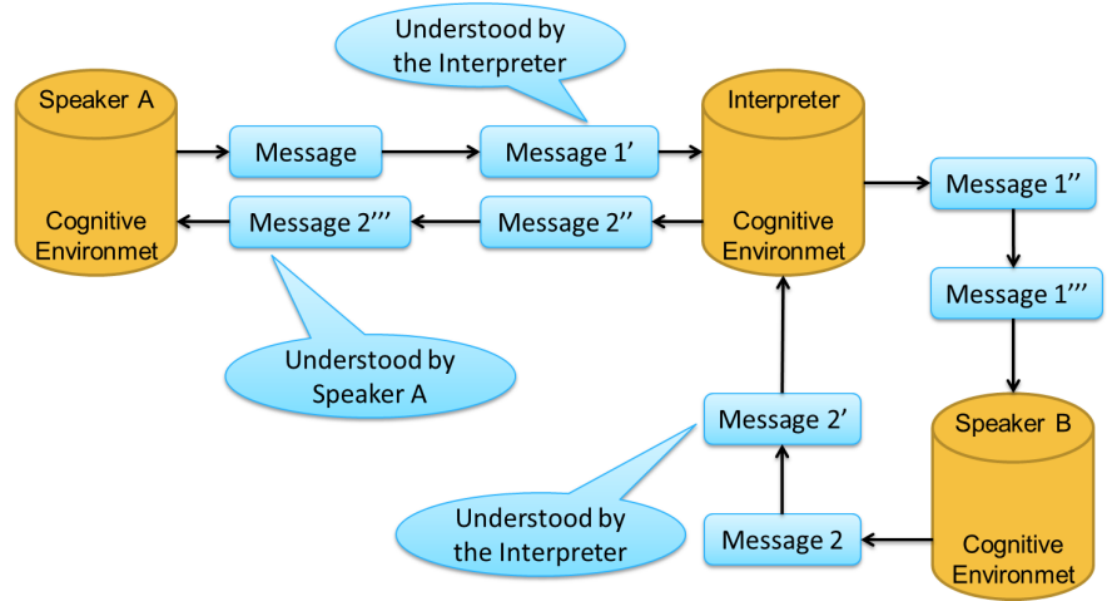

Figure 1. Communicative Act of Interpreting (Bu Yiqing 2009, p. 19)

In this complex communicative act, interpreting is integrated into the whole communicating process, and contributes to complexity by dividing the whole process into two parts: one between speaker A and the interpreter and the other between the interpreter and speaker B.

"Interpreting is a communicative activity, during the process of which, an interpreter orally transfers what he/she receives and comprehends in one linguistic form into the other language accurately and immediately, so as to pass on

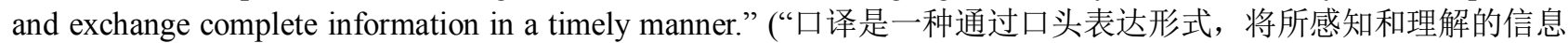
准确而又快速地由一种语言形式转换成另一种语言形式, 进而达到完整并即时传递交流信息之目的的交际行 为。”) (Mei Deming 2006, p. 6) So in the final analysis, interpreting is essentially a communicative activity, and the interpreter shoulders the responsibility to convey language meaning.

\section{C-E INTERPRETING OF POLITICAL NEOLOGISMS}

Interpreting Chinese political neologisms has its own distinctiveness, which poses greater demands on the interpreters' abilities. Here is a detailed analysis of what interpreters need in order to interpret Chinese political neologisms, based on Searle's theory. 
For some Chinese political neologisms borrowed from English, the original English versions can be directly utilized, as no confusion exists. Such instances are “峰会(feng hui, summit)”, “绿卡(lv ka, green card)”, “白皮书(bai pi shu, white paper)” and “泡沫经济(pao mo jing ji, bubble economy)”. Apart from that, some Chinese expressions have been integrated into English, known as China English, which being already familiar to the audience, can be used by interpreters. For example, “一国两制(yi guo liang zhi, one country, two systems)”, “高度自治(gao du zi zhi, high degree of autonomy)” and “三个代表(san ge dai biao, three represents)” are deemed acceptable by foreign media. In recent years, adoption of Chinese expressions into English seems on the rise, as we can see new China English words like “两会(liang hui, NPC \& CPPCC)” and “不折腾(bu zhe teng, avoid self-inflicted setbacks)” have been incorporated into foreign press and Wikipedia.

Nevertheless, real-life cases are much more complex. For a large scope of occasions, the above-mentioned strategies do not comply. Interpreters need to adopt literal interpreting, literal interpreting plus explanation and free interpreting accordingly.

To start with, literal interpreting can be used on certain occasions. Literal interpreting preserves the form, including images and rhetorical devices of the source language. One such occasion is when interpreters make judgments that literally interpreted versions of target language without explanation are within the comprehension abilities of the recipients. This calls for mobilization of interpreters' Network knowledge to grasp the speakers' intentional states, and activation of their Background knowledge to have correct estimates of the audience's cognitive abilities. Examples in point are “廉租房(lian zu fang, low-rent housing)”, “经济特区(jing ji te qu, special economic zone)” and “税费改革 (shui fei gai ge, reform of taxes and charges)". The other occasion is that the literally interpreted versions are regarded to be understood by the audience if they put them within the context. For instance, when the political neologism “一圈 两翼(yi quan liang yi)" was first put forward by an official of Chongqing Municipal Government during a press conference, the interpreter gave a literally interpreted version "one circle with two wings", which is acceptable because the interpreter made a correct prediction that the speaker would give further explanations later to be interpreted. During this process, the interpreter showed rich Background knowledge by taking stock of the situation correctly.

Despite the fact that literal interpreting is time-efficient, which conforms to the requirements of interpreting, there exist some occasions when explanation is essential. Interpreters need to give social rules due attention. C-E interpreting of Chinese political neologisms is mostly for introducing and elaborating on China's policies and stances to foreign countries. Thus it is of paramount significance that abundant clear information is provided. At the same time, as for political neologisms, foreign audience may not have adequate understandings, and their knowledge about China and the current context may not suffice to enable them to master the intended meanings. Under such circumstances, literal interpreting with explanation is suggested. For the accurate explanation to be offered, need arises that the interpreter concurrently motivates his/her Network knowledge to grasp the intention of the speaker and Background knowledge to hold audience's knowledge up to the current situation. Here Network-Background Theory is again much instructive. Some more instances are listed. 三通(san tong) three direct links across the Taiwan Straits, namely, links of trade, transportation and mail services; 菜篮子工程(cai lan zi gong cheng) vegetable basket project aimed to improve the market supply of vegetables, meat, fruit and other non-staple food; 草根工业(gao gen gong ye) grass-roots industry, which refers to village and township enterprises that take root among farmers and grow rapidly like wild grass. Added explanations may be omitted when these neologisms appear more than once within a same context.

Further, some Chinese political neologisms, such as those with rhetorical devices and those in abbreviated forms, require free interpreting, which aims to convey sufficient meanings in an acceptable way by the foreign audience at the cost of sacrificing the linguistic forms of source language. To illustrate, as to the neologism “三高农业(san gao nong ye)", one may put it into "three high agriculture", which has ambiguity and may lead the audience to confusion. Under such conditions, the interpreter needs to show Background knowledge by having a clear understanding of the situational context and taking into account that political discourse interpreting first demands clarity to show China's policies and positions to the outside world, and that the foreign audience may lack knowledge about this term. Then the interpreter tries to activate his/her own Network knowledge, and may add some words to produce a clearer English version "high-yield, cost-efficient and high-tech agriculture". More examples are as follows. 三公问题(san gong wen ti) use taxpayers' money for car rides, foreign trips and entertainment; 灰色收入(hui se shou ru) income from moonlighting; 推派风(tan pai feng) common practice of irrational quotas. In some other Chinese political neologisms, roughly the same meanings are reiterated either to form four-character expressions or to give emphasis to the ideas. Omission and generalization can be utilized for interpreting these neologisms. For instance, “医德医风(yi de yi feng)” can be interpreted as “medical ethics”, with the word “ethics” conveying the meaning of both “德(de)” and “风(feng)”, and “上 有政策(shang you zheng ce), 下有对策(xia you dui ce); 有令不行(you ling bu xing), 有禁不止(you jin bu zhi)” can be generalized as "disobey orders and defy prohibitions".

\section{CONCLUSION}

Quality of C-E political neologism interpreting is closely associated with whether China is able to let the world have better understandings of its policies. 
In Searle's Intentional Theory of Meaning, he emphasizes the importance of social rules and of communicators' mental capability in producing and understanding meaning, concluding his Network-Background Theory.

According to this theory, interpreters need to fully activate their Network knowledge to get the intentional states of the speakers by improving their knowledge structures. Thus, when interpreting political neologisms, first of all, interpreters need to comprehend various shades of meanings of the neologisms to ensure speakers' intended meanings or intentional states are well grasped. Meantime, interpreters need to mobilize their Background knowledge. The situational context and foreign audience's possible knowledge of China should be considered. This poses a requirement for interpreters to enhance their political sensitivity and cultural awareness.

\section{ACKNOWLEDGEMENTS}

This work is supported by grant CFTD194032 from Center of Faculty Teaching Development, University of Shanghai for Science and Technology, grant ZZslg18027 from Shanghai Municipal Education Commission, and College of Foreign Languages, University of Shanghai for Science and Technology.

\section{REFERENCES}

[1] Bu, Yiqing. (2009). A Tentative Approach to Interpretation Accreditation Tests - Interpretation from a Communicative Perspective. Dissertation, Shanghai International Studies University.

[2] Bussmann, Hadumod. (1996). Routledge Dictionary of Language and Linguistics. London \& NY: Routledge.

[3] Chilton, Paul. \& Christina Schäffner. (1997). "Discourse and Politics". Discourse as Social Interaction (Discourse Studies: A Multidisciplinary Introduction, Vol 2.). London: Sage Publications, 206-230.

[4] Foucault, Michel. (1984). “The Order of Discourse”. Language and Politics. NY: New York University Press, 108-138.

[5] Huang, Birong. (2010). A Study on Intentional Theory of Meaning. Foreign Language Research, 157, 1-5.

[6] Jacob, Pierre. (2010, August 31). "Intentionality". Stanford Encyclopedia of Philosophy. [Online]. Available: http://plato.stanford.edu/. [accessed 2019, 13 January].

[7] Jaworski, Adam. \& Nicolas Coupland. (1999). "Introduction”. The Discourse Reader. London: Routledge, 1-3.

[8] Li, Yue'e \& Fan, Hongya. (2002). Discourse Analysis. Shanghai: Shanghai Foreign Education Press.

[9] Mason, Kelby., Sripada, Chandra., \& Stich, Stephen. (2011). The Philosophy of Psychology. In D. Moral (ed.), Routledge Companion to Twentieth-Century Philosophy. London: Routledge, 1-46.

[10] McNair, Brian. (1995). An Introduction to Political Communication. London: Routledge.

[11] Mei Deming. (2006). An Advanced Course of Interpretation. Shanghai: Shanghai Foreign Language Education Press.

[12] Searle, John. (1965). What is a Speech Act?. In M. Black (ed.). Philosophy in America. London: Allen and Unwin, 221-239.

[13] Searle, John (1983). Intentionality: An Essay in the Philosophy of Mind. Cambridge: Cambridge University Press.

[14] Searle, John. (1999). Mind, Language and Society: Philosophy in the Real World. New York: Basic Books.

[15] van Dijk, Teun A. (2001). "Critical Discourse Analysis". Handbook of Discourse Analysis. Oxford: Blackwell, 352-371.

[16] Wilson, John. (1990). Politically Speaking: The Pragmatic Analysis of Political Language. Oxford: Basil Blackwell.

[17] Xu Haiming. (1998). A Comparative Study on Husserl, Grice and Searle's Intentional Theories of Meaning. Journal of Foreign Languages, 114, 64-69.

Xiaowen Ji was born in China in 1991. She obtained her Master's degree in English Language and Literature from Shanghai International Studies University (SISU) in 2014, and her PhD degree in the same major from the same university in 2017, with a year as a visiting PhD researcher in Leiden University, the Netherlands, supported by China Scholarship Council.

She is currently a lecturer in University of Shanghai for Science and Technology. Her research interests include multilingual development, interpreting studies, and teaching of English as a second language. She can be reached through jixiaowensisu@163.com. 